\title{
8 \\ THE STRUCTURE OF INDUSTRIAL PRODUCTION AND THE BOUNDARIES BETWEEN FIRMS AND MARKETS
}

\author{
Giovanni Dosi and Roberta Salvatore
}

\section{INTRODUCTION}

A puzzling feature of contemporary industrial structure is the relative stability of a skewed distribution of firm- and plant-sizes over all the industrial history for which data can be estimated: approximately, a Pareto distribution. In turn this plausibly implies that the relative frequency of activities and transactions occurring within single organizations as compared to those mediated through the markets has remained roughly constant, despite the secular growth of industrial output and despite the secular tendency toward technical specialization among production tasks (i.e. an increasing "division of labor"). Two other phenomena add to this puzzle. First, sectoral distributions may well look different from the aggregate one (over "industry" or "manufacturing" as a whole) and seem to be also more volatile over time: the clothing industry is quite different from that producing mainframe computers, in terms of size distributions, degrees of concentration, and probably also in terms of variability of market shares of individual firms.

Second, despite the statistical aggregate stability of the distribution, the relative ranking of single firms is quite volatile: it suffices to compare the Fortune list today with that from one of the earliest years.

The interpretation of this evidence involves major theoretical questions: what explains the approximate borders between market and organizations? How do they change over time? How does one account for the coexistence of widely different sizes even within the same productive activity? How does one reconcile the sectoral evidence on diverse patterns of entry, exit, and changes in market shares with rather stable aggregate size distributions?

Any answer to these questions also entails direct consequences for the "political economy" of contemporary economic systems. In particular, it has been suggested by several authors that the changes in technologies and production organization in the last couple of decades are part of a secular transformation in the boundaries between corporate organizations and markets, biased by novel advantages of smaller-size firms. (And, of course, for this interpretation to hold, one must also assess the stability of these advantages and show their long-term effects on industrial structures.)

In this chapter we shall present some ideas and conjectures for an answer to the foregoing questions, drawing from the evidence and theoretical results which have emerged within "evolutionary" analyses of industrial dynamics. In the second section of 
the chapter, we shall set the background of our work by briefly discussing some interpretations of firms' boundaries and industrial structure from the economic literature. The next section presents a few elements for a theory of firms' boundaries based on the organizational and technological specificities of their "core competences" and on the features of the competitive environments where they operate. In a fourth section we present a simple stochastic model of firm growth, which, however, maintains some of the stylized phenomena of firm-and industry-specificities identified by "evolutionary" industrial economics. We show via simulations that a Pareto-type size distribution is likely to emerge by aggregation of sectoral dynamics which may well diverge from it. Next, we study the consequences for industrial structures of a generalized "technological shock" which, supposedly, "devalues" the competitive capabilities of incumbent firms and plausibly favors smaller entrants. The ensuing changes in the size distributions of firms look somewhat like those which have been empirically identified in recent data. However, we shall argue that permanent competitive biases in favor of smaller-size firms must involve also a continuous "evolutionary superiority" of the organizational and technological knowledge embodied in the entrants vis-à-vis the incumbents. This, in our view, is most unlikely. Rather, one may plausibly interpret the current transformations in "industrial demography" as the outcome of deep modifications in the patterns of technological learning and market selection, which, nonetheless, do not eliminate the advantages that size, cumulative learning, vertical integration, and horizontal diversification, under certain circumstances, provide.

\section{REGULARITIES IN INDUSTRIAL STRUCTURES AND INDUSTRIAL EVOLUTION}

As mentioned at the beginning of this chapter, the evidence on the size frequencies of business firms shows remarkable stability of skewed distributions, resembling rather closely Pareto distributions (cf. Ijiri and Simon 1977 and the bibliography cited there). Of course, if each firm were specialized in one single product, the aggregate dynamics of size distributions would be simply the outcome of

a) changes in output shares of each firm, and

b) product-specific output dynamics (i.e. demand changes).

However, most firms are multiproduct and, thus, the observed aggregate distributions must also account for the degrees to which firms are vertically integrated and horizontally diversified (i.e. they manufacture various products sold in different markets), and also for the fact that firms may merge, divide, sell off parts of themselves, etc.

For the time being, let us stick to the simpler-and far from realistic-hypothesis of single-product firms. A long tradition, going back at least to Gibrat (1931), has shown that the observed skewed distributions can be generated via a stochastic process of proportional growth (plus some additional hypotheses which do not always have a clear empirical meaning, as briefly discussed below). ${ }^{1}$ If $X_{i, t}$ is some measure of the size of firm i size at time t (e.g. turnover, employment, etc.) suppose that 


$$
X_{i, t} / X_{i, t-1}=\alpha \cdot \Phi_{i}\left(X_{i, t-1}\right) \cdot \varepsilon_{t-1}
$$

where $\alpha$ is the growth rate of the market, common to all firms, $\boldsymbol{\Phi}\left({ }_{+}\right)$is a function expressing the dependence of current upon past size, and $\varepsilon_{t-I}$ is a random multiplicative term. Assuming that

$$
\Phi\left(X_{t-1}\right)=X_{t-1}^{(\beta-1)}
$$

for all firms, and taking logarithms, we have

$$
\log X_{i t}=\log \alpha+\beta \log X_{i t-1}+\log \varepsilon_{t-1} .
$$

The proportional growth hypotheses (Gibrat's law) implies, first, that $\beta=1$ (i.e. the rates of growth do not depend on initial size) and second, that $\log =N\left(o, \sigma^{2}\right)$ is independentlydistributed and in particular is independent of initial size. With some additional assumptions in order to prevent the variance of equation 2 from exploding this equation ${ }^{2}$, one actually obtains a skewed limit distribution (a Yule or a Pareto distribution) which appears to fit rather well aggregate empirical data (Ijiri and Simon 1977). "Gibrat's Law" has also been tested in various forms on more disaggregate data, with rather mixed outcomes. In particular, most evidence seems to reject the hypothesis of independence of the variance of growth rates from initial size, and some evidence appears also to restrict the applicability of the "law" to particular size classes. ${ }^{3}$ We are not going to discuss here the details of either Gibrat type stochastic models of firm growth or the supporting evidence. A few general remarks will suffice.

\section{Neutral combinations between market and organization?}

First, a general hypothesis of independence of growth rates from the size that firms have already achieved seems, at least prima facie, at odds with a Marshallian theory of production based on U-shaped cost curves. ${ }^{4}$ More generally, the few attempts at accommodating the evidence with equilibrium models of industrial structures seem to us rather far-fetched: they rely, for example, on ad boc auxiliary assumptions on capital adjustment and unobservable distributions of scarce managerial talents (Lucas 1978) or on stochastic processes of convergence to supposedly given optimal techniques under imperfect information and perfect rationality (Jovanovic 1982).

Indeed, the most likely candidates for a theory of production compatible with Gibrattype models imply constant returns to scale: no persistent scale-biased factor influences growth opportunities (an exception being Kalecki's model with increasing constraints to growth related to financial factors). At the extreme, all possible combinations between organizations and market are neutral equilibria. That is, all possible distributions of industrial structures, ranging from monopoly to perfect competition, can be expected exante to show identical efficiency properties. 
The "structure" (i.e. the relative invariant size distribution which data reveal) can be theoretically generated by some random process with little or no past memory, 5 plus some auxiliary restrictions (such as on birth and death rates). In this case, the random process stands for a multiplicity of minor factors which temporarily make one firm more (less) efficient than the competitors, but are not persistent over time. (These considerations, mutatis mutandis, apply also to stochastic models based on serial correlations of growth rates with decaying effects over time.) Alternatively, one could also interpret the random process applied to growth rates not as the outcome of a multiplicity of small efficiency-related "shocks," but rather as the random degrees of success of some extra-economic variables. In fact, this interpretation can easily be drawn from "radical" theories of the firm (see Marglin (1974) and the discussion in Putterman (1986)). Firms exist essentially because of an asymmetric distribution of power in society. Hierarchical control is primarily finalized to the extraction and the appropriation of an economic surplus. Plausibly, firms grow as a function of the (stochastic) success of their owners in accumulating and concentrating capital in their hands. Indeed, we do not have any difficulty in accepting factors related to power and control among the determinants of the characteristics of firms and industries as we see them, beyond and in addition to efficiency considerations. However, we are rather skeptical of a general "neutrality" hypothesis (i.e. "all forms of industrial structures are identical in terms of efficiency"), either in the Gibrat-type interpretation or in the "radical" one. To trivialize, it is difficult to imagine a Boeing aircraft produced with the same efficiency in an Italian industrial district by thousands of family-run firms, or, conversely, a (now defunct) East German Kombinat producing fashion garments with the same efficiency and creativity as an Italian district. More generally: microeconomic evidence, admittedly quite impressionistic, seems to suggest that in each industrial activity there are some "typical ways" of organizing production. There can be more than one, but not very many. That is, there can be a few combinations between organization and markets that are "neutral" in terms of efficiency, but the set is small and possibly not dense. This also implies that at a disaggregated level one may not expect to find either the structure or the Gibrat-type growth that one sees in the aggregate.

\section{Industry and firm specificity}

Second, a few analyses within and outside an "evolutionary" approach (cf. Nelson and Winter 1982, Dosi et al. 1988, and the review in Dosi 1988), have emphasized the sectoral specificities in the process of learning, innovation, and imitation. If, as is likely, there is a direct link between innovation and growth, these specificities of learning ought to have a direct link with the "explanation" of why industrial structures are what they are and how they change. In particular, it has been suggested that various activities present different degrees of technological opportunity, that is, a different scope for improvements in products and processes on the grounds of a given knowledge base, and also a different "easiness" in achieving these improvements. (One way of formalizing these differences is in terms of the probability distributions of achieving an $x$ percent improvement in some performance characteristics of a product or a process, given some search effort, say a one dollar investment in R \& D). Technologies and sectors have also been found to differ in 
terms of appropriability conditions, i.e. the effectiveness through which innovations can be shielded from imitation by competitors. Moreover, according to the features of the process of innovative search and the knowledge upon which it draws, the innovative success of individual firms may show varying degrees of serial correlation, often referred to as the cumulativeness of innovative activities. Finally, it has been argued elsewhere that radical changes in the knowledge bases, procedures, and directions of technological change, i. e. a change in the "technological paradigm" (Dosi 1982) also imply significant changes in the relative innovative capabilities and growth potential of firms embodying "old" or "new" competences.

These findings have direct implications on the evolution of industrial structures which can be easily seen by comparison with the stochastic interpretation discussed earlier.

- Differences across industries in technological opportunities (assuming some positive correlation between innovation and growth) imply different means and variances of the stochastic term in equation 1. Moreover, if "opportunities" change over the development of each technology, one should also expect correlated changes in the distribution of the

- Appropriability of innovation, cumulativeness of technological advances, and tacitness of some elements of technological knowledge imply some firm-specificity in the factors that foster or hinder growth. The findings from the economics of innovation, as well as complementary findings from business studies, suggest that $\boldsymbol{\Phi}_{\mathbf{i}}($. ) functions in equation 1 can hardly be assumed to be identical across firms. Some firms may be persistently "better" or "worse" than others. In turn, that means that every pattern of evolution of industrial structures must not only be interpreted in terms of a multiplicity of little transitory shocks on individual growth opportunities, but also account for the interaction among firms that may be persistently different in their technological and organizational characteristics.

- Differential degrees of appropriability and cumulativeness, and different characteristics of the knowledge underlying innovative activities are also likely to imply a different entry condition in each industry. For example, in industries characterized by highly idiosyncratic knowledge, by serial correlation in learning, and by high appropriability of innovations, one may expect the rates of entry to be low. The opposite should hold for industries where innovation can draw on a variety of sources of freely available knowledge, appropriability is low, etc. 6

- Abandoning the assumption of single-product firms, the variegated sources and procedures of learning and innovation are bound to affect the corporate patterns of horizontal diversification and vertical integration and, thus, also the structure of individual industries and of manufacturing as a whole.

To summarize: the microeconomic findings on the innovation process high-light rather permanent factors accounting for learning specificities of both firms and industries. If, as is the case, innovation is a crucial ingredient of corporate growth, then a satisfactory interpretation of the emergence of the observed industrial structures should account for such processes of differentiated learning and the ensuing competition among heterogeneous agents.

Such an interpretation ought to have two major components: first, an account of the 
"structures" generated by learning and market selection dynamics in individual industries, and second, an explanation of the interlinked dynamics of firm diversification, vertical integration, specialization, entry, and exit from the various markets. Let us start from the latter.

\section{THE STRUCTURE OF MODERN CORPORATIONS: THEIR CHANGING BOUNDARIES AND THEIR COHERENCE ${ }^{7}$}

There are at least two remarkable characteristics of the boundaries of the modern corporation that ought to intrigue theorists:

a) their multiproduct scope, and relatedly

b) the non-random distribution of product porfolios across firms.

That is, the activities of the modern corporation display a considerable degree of relatedness, what we call coherence: thus Shell Oil Company is primarily in the oil business, IBM is in information technologies, Intel is in semiconductors, ICI and Dupont are primarily in chemicals, and Boeing is in areospace. Setting aside for the moment the conglomerate form of business organization, what is remarkable about the majority of firms is their relative "coherence" in their lateral and horizontal business activities.

Admittedly, the boundaries of the firms are sometimes quite fuzzy, with interfirm agreements, joint ventures, and consortia rendering precise delineations of the firms' activities imprecise. Still, even interfirm agreements, joint ventures and consortia exhibit a degree of coherence with other activities in which associated firms are involved. At a very superficial level, the most salient attribute of diversification is that it tends to increase over time, and new product lines bear certain technological and market similarities with the old. Thus firms generally begin with a single product and subsequently become multiproduct rather than the other way around; and new product lines very often, though certainly not always, utilize capabilities common with existing product lines. Indeed, many prescriptions in business economics with respect to diversification strategies are characterized by their emphasis on the desirability for firms to "stick to their knitting," though such prescriptions rarely specify what the knitting is to which firms should stick.

The casual empiricist is also likely to remark upon the fact that rates of diversification vary among firms. Thus Western Union has been in the telegraph business and little else for over a century. Shell Oil has been in petroleum for almost as long, having added petrochemicals only in the postwar years. $3 \mathrm{M}$, on the other hand, has diversified into an extremely broad range of coatings, adhesives, and related products in the last two decades. Corporate diversification is also a phenomenon that can expand and contract. Firms not only add business, they also commonly divest. Indeed, there often appears to be a degree of circularity of the fashion in which new businesses are added and subsequently divested. This is particularly so when corporations diversify through acquisition. ${ }^{8}$ On the other hand, corporations often display remarkable similarities with respect to their diversification strategies. Almost everywhere car and truck companies have diversified into buses, e.g. Mercedes, Leyland, F3iat, GM, and Renault all make 
cars and buses. The challenge is to develop a theory to explain not only coherence, but also similarities and differences in the nature of coherence across firms and industries.

Coherence, we should point out, is different from "specialization". Specialization refers to the performance of particular tasks in particular settings. This is the manner in which Adam Smith implicitly defined the concept, and it is the way we will use it. In the famous pin making example, Smith referred to specialization in terms of particular tasks. Thus a firm may exhibit coherence though it may not necessarily be specialized. We are, accordingly, defining coherence in a multiproduct sense. A firm exhibits coherence when its lines of business are related, in the sense that there are certain characteristics common to each. Coherence is increased with the number of common characteristics present across lines of business and the level to which they are present. A corporation fails to exhibit coherence when common characteristics are allocated across firm's lines of business in no greater frequency and to no greater depth than could be explained by chance.

Neoclassical theories of industrial organization, including the so-called new industrial organization (e.g., Tirole 1988) has little to say about diversification and integration issues. While there is some development of market power and economies of scope explanation for diversification, these theories are without strong organizational implications. Thus one can "explain" diversifications through notions of "full line forcing" or "economies of scope," but such theories rarely explain why a set of contracted relationships among specialist firms could not accomplish the same objectives. In this regard, consider economies of scope. If the production of $x_{1}$ and $x_{2}$ involves scope economics, then:

$$
c\left(x_{1}, x_{2}\right)<c_{1}\left(x_{1}, 0\right)+c_{2}\left(0, x_{2}\right)
$$

However, in standard treatments, the organizational discussion of the joint cost function $c$ $\left(x_{1}, x_{2}\right)$ is never explained. The amalgamation implied by the cost function could be accomplished by a variety of organizational mechanisms, including contracts (Teece 1980, 1982). A theory of multiproduct organizations thus does not emerge from the economics of scope literature or from other theories of the firm.

Admittedly, transaction costs considerations contribute significantly to explaining the degrees of vertical integration, that is "make or buy" decisions with regards to the firm inputs (Williamson 1975, 1985). However, exchange relations - from which transaction costs may derive - alone, do not appear to be the crucial domain in which to search for the causes of the horizontal boundaries of the firm. Drawing from another work of one of us, we advance the fundamental proposition that the boundaries of the corporation need to be understood not only in terms of transaction cost considerations, but also in terms of learning, path dependencies, technological opportunities, selection, and complementary assets (Dosi, Teece, and Winter 1992).

\section{Learning}

A fundamental characteristic of economic activity is that it provides the opportunity for 
learning. Learning is a process by which repetition and experimentation enable tasks to be performed better and faster and new production opportunities to be identified. In the context of the firm, if not more generally, learning has several key characteristics. First, it is generally cumulative. What is learned in one period builds upon what was learned in earlier periods. Individual knowledge gained through learning must, however, be constantly used in order to be preserved.

Corporate learning involves organizational rather than individual skills. While individual skills are of relevance, their value depends upon their employment in particular organizational settings. Learning processes are intrinsically social and collective phenomena. Learning occurs not only through the imitation and emulation of individuals as with teacher-student or master-apprentice, but also because of joint contributions to the understanding of complex problems. Learning requires common codes of communication and coordinated search procedures.

The knowledge generated by such activity resides in organizational "routines." Routines are patterns of interaction which represent successful solutions to particular problems. These patterns of interaction are mainly resident in group behavior, though certain subroutines may be resident in individual behavior. Because of the complexity of such behaviors, knowledge embedded in routines cannot be fully captured in codified form. That is, it has a tacit dimension that often cannot be readily articulated. Hence, it is the routines themselves, and the ability of management to call upon the organization to perform them, that represents an organization's essential capability.

Routines can be of several kinds. "Static" routines embody the capacity to replicate certain previously performed tasks. Needless to say, such routines are never entirely static, because with repetition routines can be constantly improved. "Dynamic" routines are directed at learning and new product/process development. Thus $\mathrm{R} \& \mathrm{D}$ activity proceeds through the employment of routines to ascertain where to probe, how to probe, and how much to probe.

Because routines involve a strong tacit dimension, they may not be easy to imitate. To the extent that it is so, routines contribute to a firm's distinctive competences and capabilities. Such capabilities, by virtue of their evolution in particular environments and organizational contexts, are likely to differentiate firms from each other and provide the basis for differential performance vis-à-vis competitors.

\section{Path dependencies}

In standard textbook theories firms have an infinite range of technologies from which they can choose, and markets that they can occupy. Changes in product or factor prices will be responded to instantaneously, with technologies moving in and out according to a value maximization criterion. Oliver Williamson $(1975,1985)$ has done much to enrich the standard treatment by introducing transaction-specific assets. Such assets have idiosyncratic uses and cannot be redeployed without substantial loss of value. Williamson demonstrates how the need for such assets generates particular requirements with respect to an industry's governance apparatus.

The notion of path dependencies goes even further than notions of irreversibilities implied by transaction cost economics. It recognizes that "history matters." Thus a firm's 
previous investments and its repertoire of routines (its "history") constrains its further behavior. This follows because learning tends to be local. That is, opportunities for learning will be "close in" to previous activities and will thus be transaction- and production-specific (Teece 1988). This is because learning is a process of trial, feedback, and evaluation. If too many parameters are changed simultaneously, the ability of firms to conduct meaningful quasi-natural experiments is attenuated. Thus, if many aspects of a firm's learning environment change simultaneously, the ability to ascertain cause-effect relationships is confounded because cognitive structures will not be formed and rates of learning diminish as a result.

\section{Complementary assets}

Related to path dependencies is the existence of complementary assets. Prior product and commercialization activities require and enable firms to build such complementarities. Such capabilities and assets, while necessary for the firm's prior activities, may have other uses as well. Such assets typically lie downstream from product-process development in the value-added chain.

The presence of complementary assets, particularly those that can be enhanced by innovation, helps steer the evolution of new technologies. The reason why Singer Sewing Machine got into the furniture business was related to the fact that it had designed and manufactured sewing machine tables to help facilitate the sale of sewing machines. Thus, firms' path dependencies are not just technological in nature. Paths are generated by technological trajectories and constrained further by the complementary assets the firm develops over time.

\section{Technological opportunities}

The concept of path dependencies can be given further meaning through the consideration of an industry's technological opportunities. As mentioned above, how far and how fast a particular area of industrial activity can proceed is due to the technological opportunities that lie before it. Such opportunities are partly a lagged function of foment and diversity in basic science, and partly the outcome of search activities by firms themselves. The depth and width of technological opportunities in the neighborhood of a firm's prior research activities are likely to affect a firm's options with respect to both the amount and level of R\&D activity that it can justify.

\section{Convergence of path dependencies}

While path dependencies are unique, they do not necessarily run in parallel. They can both diverge or converge. The latter are of special interest, as the confluence of particular evolutionary paths (or "trajectories") can have important organizational ramifications.

Convergence may occur because of serendipity of knowledge or as an evolutionary outcome of a series of unique historical events. Thus, for example, the convergence of computers and telecommunications is the result of the application of digital microelectronics to both fields. 
The survivability of a business activity depends on the selection environment and, in particular, the level of competition (both in the product market and the capital market), public policy, and the frequency of technological discontinuities (i.e. changes in the dominant "technological paradigms").

\section{Selection environments}

Firms sell their products in markets where customers' average response to relative price changes (within the industry or among different suppliers) and to changes in relative product performance may well differ. Economic notions such as "own-price elasticity of demand" try to capture the former phenomenon. Indeed, the sensitivity and speed of demand adjustment to variations in prices and product-quality can be interpreted in terms of the "tightness" of the selection environments within which firms operate.

Selection may or may not be "tight". Whenever it is not, less efficient firms may be able to survive and possibly even prosper for quite some time. The selection environment for a product may be stronger or weaker than that for a corporation depending on how corporate management treats internal divisions and products that are not performing up to par.

The availability of free cashflows is perhaps the key regulator of selection. If a firm or a business is generating sufficient cash flow to sustain itself and take care of reinvestment needs and opportunities, it will typically be able to survive. If it does not, then it will need additional debt or equity financing. To obtain funding of either kind exposes the firm to capital market discipline that might not otherwise intervene. Hence, the capitalization and the "inherited" capital structure of the firm are likely to affect the strength of selection processes with respect to particular business units.

\section{Core competences}

A core competence (Teece 1988) is a set of differentiated technological skills, complementary assets, and routines that provide the basis for a firm's competitive capacities in a particular business. "These people are good at X"summarizes external perceptions as to the nature of these competences. Typically, such competences have an important dimension, making replication by others difficult but not impossible. Indeed, when a core competence exists, its replication proceeds either through deliberate efforts directed at internal expansion or through the exit of key individuals who collectively take certain competences with them, and then raise capital to buy the necessary complementary assets.

Great companies like IBM, Exxon, and Toyota consist of clusters of such competences. Hollow corporations, on the other hand, lack such capacities. Business gets performed under contractual agreements struck with others. When the contracts terminate, the firm's ability to deliver value evaporates. We define a hollow corporation as a business entity that does not have any core competence and uses contractual mechanisms to link particular market requirements with productive capacities. Thus a hollow corporation is a nexus of contracts for design, manufacture, distribution, and service.

Likewise, a conglomerate is a portfolio of autonomous business units held together in a 
holding company. It is a "mutual fund" of business without core competences at the corporate (holding company) level. As discussed in Dosi, Teece, and Winter (1992), we do not believe that organizations such as those that lack core compences have survival properties unless they are somehow shielded from product and capital market competition.

\section{Proposition from the theory}

A firm consists of a cluster of core competences and supporting complementary assets. The degree of coherence displayed among them depends on the interaction between learning, path dependencies and opportunities, inherited complementary assets, and selection. Specifically:

Proposition 1: Specialist firms With rapid learning and tight path dependencies, one will observe "single" product (specialist) firms growing rapidly. Compaq Computer, Sun Microsystems, Intel, Boeing, and Airbus are good examples.

Proposition 2: Vertically integrated firms With slow learning but high path dependencies and specialized assets, one can expect specialist firms with some degree of lateral integration and significant vertical integration (e.g. Exxon. Shell, Dupont).

Proposition 3: Coherent diversification With rapid learning, broad path dependencies due to the presence of generic technologies, and tight selection, one can expect to see coherent diversifiers, like IBM, Hewlett Packard, W.R.Gore, and Raychem.

Proposition 4: Conglomerates With high path dependencies, slow learning, and weak selection, we predict the emergence of conglomerates or other highly diversified companies displaying little intercorporate trading and technological transfer.

Proposition 5: Network firms With rapid learning, colliding path dependencies and tight selection, one can expect to see incumbent firms becoming enveloped in a dense skein of intercorporate relationships involving partial equity holdings or joint learning. Thus, because of the convergence of telecommunications and computers, AT\&T is becoming embedded in a thicket of intercorporate relationships. So are biotechnology firms like Genetech and Cetus because the biotechnology research paradigm yields products and processes competitive with pharmaceuticals and chemicals, to name just two examples. If learning in the relevant paths were slower, then there would be a good possibility that firms could diversify internally without the assistance of interfirm agreements.

Proposition 6: Hollow corporations With converging path dependencies, opportunities may arise for entrepreneurs to use contractual mechanisms quickly to assemble diverse capabilities directed at the development and commercialization of a particular product. We refer to such entities as hollow corporations. Unless these capabilities are underpinned by equity links and unless distinctive organizational reactions emerge to "glue" such organizations together, they will not survive, except where the selection environment is weak.

In Dosi, Teece, and Winter (1992), the details and a few interpretative consequences of these propositions are discussed. In this view, the coherence (or lack thereof) of the modern corporation is thus explained by the characteristics of learning (or its absence), path dependencies, and complementarities, mediated by transaction costs and market 
selection. Pavitt et al. (1987), in a work highly complementary to this interpretation, find that the patterns of technological and market diversification can be approximately mapped into a taxonomy of learning and innovation modes.

For the purposes of this work, two major consequences can be drawn. First, the nature of the core competences of each corporation and of the learning regimes within which it operates explains to a good extent its horizontal and vertical boundaries. Second, the observed relative stability of the output shares of the larger firms in manufacturing as a whole implies indeed that on average the characteristics of learning and market selection have not dramatically changed. Manufacturing firms-especially large firms - have been able to grow, in the markets in which they were originally established and, even more important, via diversification and vertical integration, at rates, on average, comparable to the overall market growth.

However, it follows from our interpretation that the scope for growth via horizontal diversification is not uniform across firms: on the contrary, it depends, again, on features of the "technological paradigms" which they master. The evidence on the long-term changes in the relative ranking among the largest corporations, witnesses, in our view, precisely their diversity in the opportunities and capabilities of efficient diversification (jointly, of course, with the different rates of growth of the markets in which they operate).

Clearly, each strategy of diversification or vertical integration is as such a decision of entry into an industrial activity. These strategies, together with divestment decisions, entries of new firms and bankruptcies determine the changing demography of individual industries. In turn, such demographic changes, jointly with the variables affecting the variations in market shares of each firm, determine the size distribution of business units in each industry.

\section{INDUSTRIAL EVOLUTION AND INDUSTRIAL STRUCTURES}

A major claim of evolutionary theories is not only that firms differ in their competences, innovative success, and ultimately, growth opportunities, but also that industries differ in their learning modes and in the ways diverse learning abilities affect competitiveness and market shares. In this respect, the taxonomic exercise by Pavitt (1984) suggests the existence of broad groups of industrial activities differentiated by the sources of innovative opportunities, and the size distribution of the innovating firms. Malerba and Orsenigo (1989) find robust evidence mapping the characteristics of the innovating firms into the features of sectoral technological regimes (identified by proxies for technological opportunities, appropriability conditions, the nature of the knowledge base, and the cumulativeness of innovative success). Gort and Klepper (1982) and Gort and Konakayama (1982) identify relatively robust patterns of evolution of the supply structure along the "technological life cycle" of a sample of products. Literature on the "population ecology" of firms has emphasized:

a) the sectorial differences in the rates of birth and death of firms; and

b) the significant effects of the age of firms on their growth (which often turn out to present a negative sign). 9 
Most likely, different learning regimes must also imply intersectoral differences in the variability of market shares of incumbent firms (i.e. what Caves and Porter (1977) call mobility barriers) and in the rates of entry and exit of new business units in each industry. Indeed, Audretsch and Acs (1990) find a significant empirical difference in industrial "turbulence" (defined as a synthetic measure of entry, exit, and changes in market shares of incumbents) between those industries characterized by a regime of "cumulative" learning by incumbents and those others where new entrepreneurial activities are more likely to carry innovative advantages.

Clearly, all this variegated empirical evidence prima facie conflicts at least with the simplest Gibrat-type accounts of firm growth:

a) firms (and business units) are not identical in their growth opportunities, and

b) the distribution of growth possibilities among different types of firms vary across sectors and across "regimes of innovation."

Then, how does one explain the observed industrial structures? Ideally one should be able theoretically to generate these structures on the grounds of an explicit representation of firm-specific learning process and a selection mechanism which favors (or hinders) the growth of business units characterized by above-average (or below-average) competitiveness. Consider, for example, the dynamics of market shares as from Silverberg, Dosi and Orsenigo (1988):

$$
f_{i}(t)=A\left[E_{i}(t)-\bar{E}_{i}(t)\right] f_{i}(t)
$$

where $f_{i}(t)$ is the market share of the $i$-firm at time $t ; \mathrm{E}_{i}(\mathrm{t})=\mathrm{G}\left(\mu_{\mathrm{i}}(\mathrm{t})\right)$ is the competitiveness of firm $i$-which in turn is a function of some vector of its technological and organizational characteristics $\mu_{i}(t) ; E_{i}(t)$ is the average competitiveness of the industry; and the dots stand for the rates of change. The composition of the vector $\mu$, its changes over time and the $G($.) function depend in principle also on the learning regimes of each industry. That is, the learning mechanism specific to each technological paradigm governs the transition probabilities in $\mu_{i}(t)$. A necessary condition for a Gibrat-type process of growth is that

$$
\left(\mu_{i}^{j}\right)_{t+1}=\left(\mu_{i}^{j}\right)_{t}+\varepsilon
$$

for every $j$ component of $\mu$, with $\varepsilon$ an independently and identically distributed (i.i.d.) random variable. However, one can easily imagine different types of dynamics, ranging between two extreme archetypes. In the first one somewhat resembling an extreme version of the "first" Schumpeter (1934), $\left(\mu_{i}^{j}\right)_{t+1}=\left(\mu_{i}^{j}\right)_{0}, \forall \mathrm{t}$ : no learning occurs and industrial innovation entirely relies on the "creative destruction" associated with the entry of new firms. The other archetype is that whereby

$$
P\left(\varepsilon>0 \mid\left(\mu_{i}^{j}\right)_{t}=\varphi\left(\left(\mu_{i}^{j}\right)_{t}\right):\right.
$$

learning is cumulative and the transition probabilities are some positive function of the 
levels of competitiveness already achieved by each firm, (somewhat resembling the "second" Schumpeter (1942).

Indeed, a major theoretical task ahead is to study the limit distributions in market shares according to different learning and selection processes. Falling short of that, here we present a model and some simulation results that try to capture by some proxies the specificities of learning and selection regimes.

Let us start from the following hypotheses:

a) In cumulative learning regimes the probabilities of exit (that is of "death" of a business unit which may or may not be equivalent to the death of the firm) decreases with the age of the firm (metaphorically, the older one gets the more experienced one becomes and more able to cope with unexpected circumstances...) The opposite applies whenever discontinuities in the knowledge base make the skills of older firms obsolete.

b) The probabilities of death decrease with size if there are some economies of scale in production, $R \& D$, etc. At the opposite extreme, they increase with size if scale mainly induces organizational rigidity and inefficiency.

c) The variance of growth rates decreases with age (which captures the idea that older firms are relatively more stable in the competences that they incorporate and the market niches that they occupy).

d) The birth rates are proportional to the number of incumbents in each industry (for some empirical evidence cf. Dunne, Roberts and Samuelson (1988)).

Formally, the survival probability of firm $i$ from time $t$ to $t+1$ in sector $k$ is

$$
E\left[I \mid a_{t}^{i} ; s_{t}^{i}\right]=\operatorname{Pr}\left\{e>p^{k}\left(a_{t} ; s_{t}\right)\right\}
$$

where $I$ is a dichotomous variable ( 0 or 1); $a$ stands for age and 5 for size, $e$ is a random variable uniformly distributed in $\{0 ; 1\}$ and $P^{k}\left(a_{t} ; s_{t}\right)$ is the survival threshold specific to each sector.

In turn, such a threshold is defined as

$$
p^{k}\left(a_{t} ; s_{t}\right)=
$$

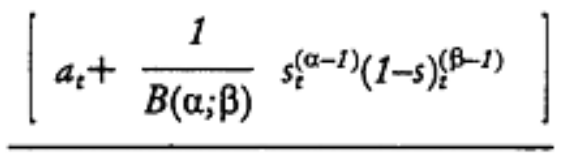

$$
\operatorname{Max}\left\lceil a_{t}+\frac{1}{B(\alpha ; \beta)} s_{t}^{(\alpha-1)}(1-s)_{t}^{(\beta-1)}\right]
$$

were $\mathrm{B}(\alpha ; \beta)$ is a Beta function. ${ }^{10}$

New firms enter according to 


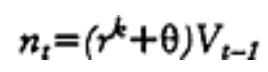

where $n$ is the number of entrants (which we shall assume to belong to the smallest size class), $V$ are the incumbents and 0 is a random variable with mean zero.

Regarding firm growth, Salvatore (1990) experiments with the alternative hypotheses of

a) a Gibrat process (i.e. independence of growth rates from initial size);

b) serial correlation; and

c) a one-period Markov process.

Here, we present the results of the latter formulation only (however the major conclusions hold for all three alternative specifications). Each firm-whose size is supposedly measured in terms of employees - grows according to

$$
g_{i, t}=g_{i, t-l}^{\delta} \varepsilon_{i, t}
$$

where $g$ is the growth rate of firm $i$ and $\varepsilon_{i, t} \cong N\left(O ; \sigma_{a}\right)$ is a normally distributed random variable whose variance decreases with the age of the firm.

In this model, the evolutionary specificities of each sector are roughly captured by the influence of size and age on survival probabilities. By trying different combinations of $\alpha$ and $\beta$ in equation 4 one can generate four "archetypical" sectors, with "sector 1": decreasing returns to scale (and, thus, "evolutionary" advantage of smaller sizes); "sector 2 ": increasing returns to scale (i.e. higher probability of survival of bigger firms); "sector 3": a U-shaped probability function (small and very big firms have the highest survival probability, which loosely recalls Pavitt's description of "science-based" sectors industries, suggesting the permanent coexistence of big oligopolies and small "Schumpeterian" firms); "sector 4": an inverted U-shaped function (i.e. there is plausibly a minimum efficient scale, beyond which organizational inefficiencies start operating). Moreover, age acts in equation 4 as a shift parameter which moves the survival function upward or downward and should implicitly account for the positive or negative "evolutionary value" of past experience. Hence, one may get 12 typologies of industrial evolution (the four basic relationships between size and probability of survival combined with positive, negative or null effect of age).

We do not have any precise idea on the empirical frequencies of the various "types," but plausibly they tend to capture a good deal of the empirical variety of industries, ranging from cases where both scale and cumulative experience determine a differential competitiveness to the symmetric opposite wherein smallness, flexibility and "novelty" are major evolutionary advantages.

Given 11 size classes, the simulations study the size distributions after 100 runs, starting with a uniform distribution across classes. Interestingly, most distributions so generated depart to a greater or less extent from the Pareto distribution with a density function 


$$
f(x)=q x^{-(1+q)}
$$

and a right-cumulated function

$$
F(x)=x^{-q}
$$

As an illustration, we present in Figures 8.1 to 8.4 the actual distributions and those obtained with OLS estimates of the logs of equation 7 on the four "archetypical" sectors (assuming no effect of age on survival thresholds).

There is no striking conflict between these results and the little we know about the variety of industrial structures at a very disaggregated level: certainly, it does not contradict the evolutionary proposition that the "boundaries" between organizations and markets are influenced by the industry-specific features of learning and selection.

Further, we suggest that

a) manufacturing-wide Pareto distributions are the outcome of aggregation over widely different evolutionary processes and industrial structures, and

b) such aggregate distribution tend to be maintained as long as on average the conditions of learning and selection do not dramatically change.

To see the plausibility of the first proposition, let us extract 20 samples of 100 firms each from the final-year distribution of firms in the twelve "types"

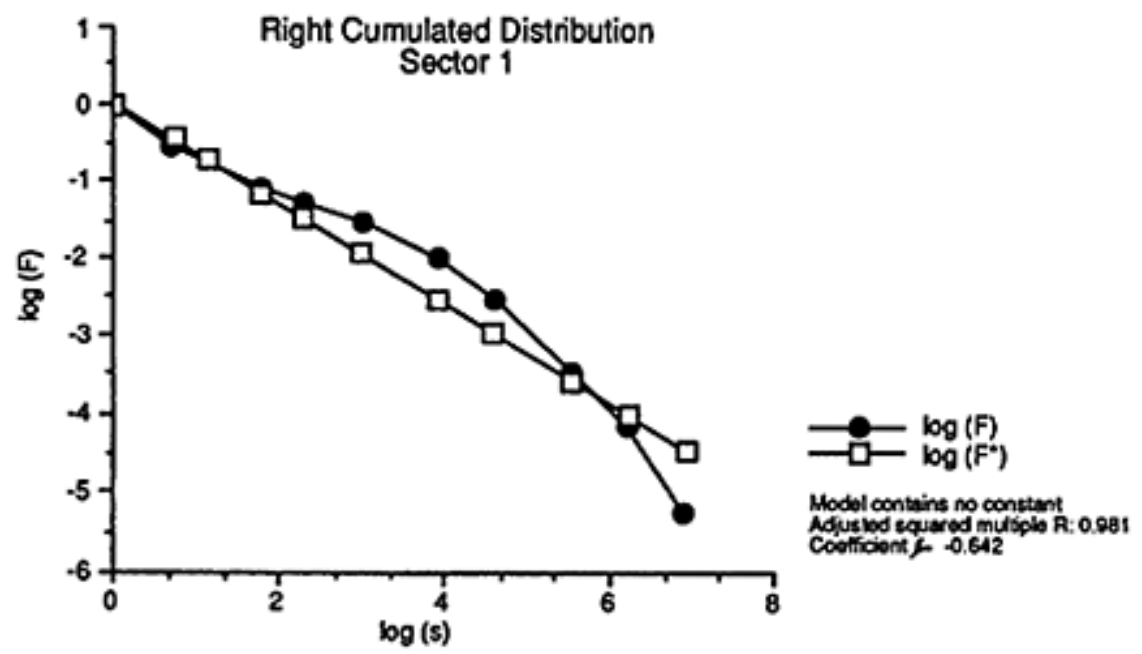

Figure 8.1 Right cumulated distribution (Sector 1) 

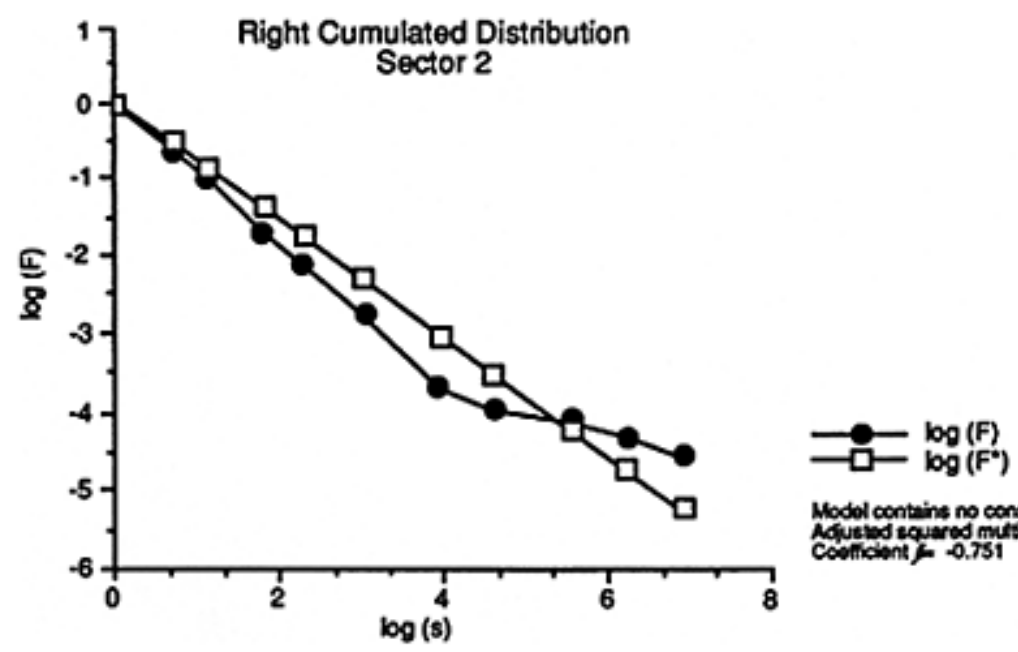

Modol contains no constant AdNetiod squarod mutspio R: 0.200 coolliciont $f=0.751$

Figure 8.2 Right cumulated distribution (Sector 2)

of industries that the model generates. As can be seen from Fig.5, the fit of a Pareto distribution is quite close, even if it was not so in most of the underlying sectors.

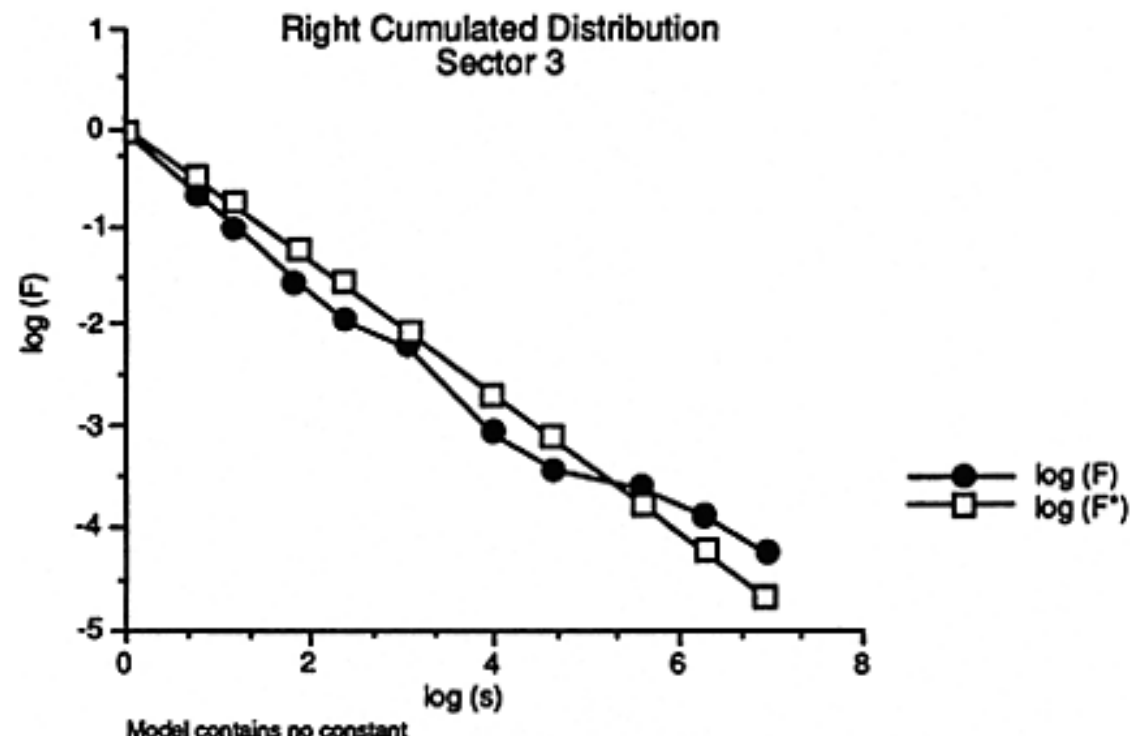

Model contains no constant

Adjustod squared multiple R: 0.968

Standard error of estimato: 0.311

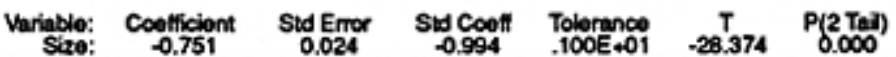

Figure 8.3 Right cumulated distribution (Sector 3) 

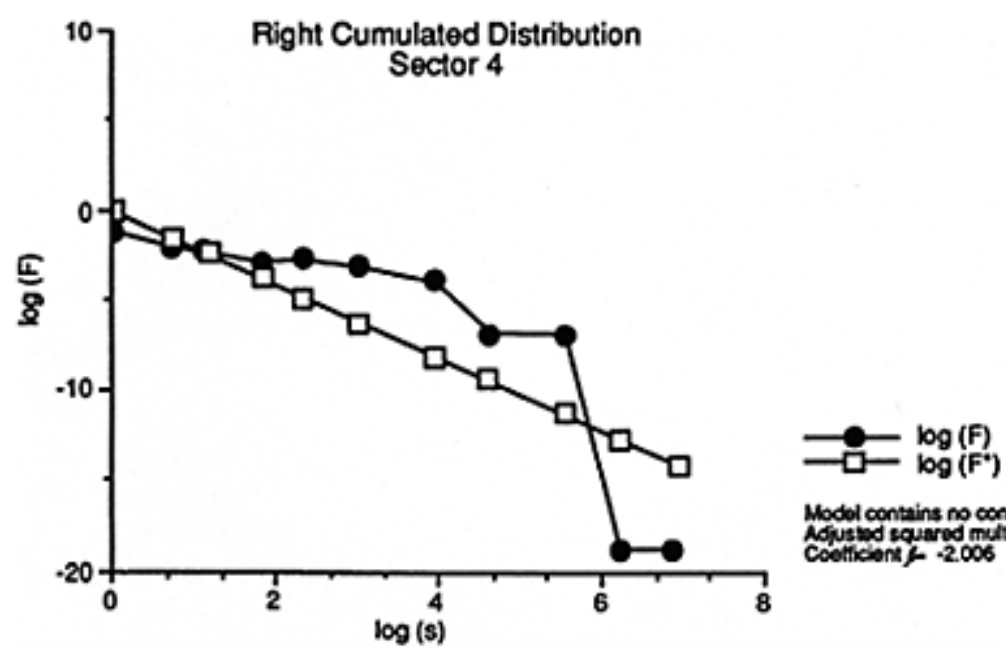

Figure 8.4 Right cumulated distribution (Sector 4)
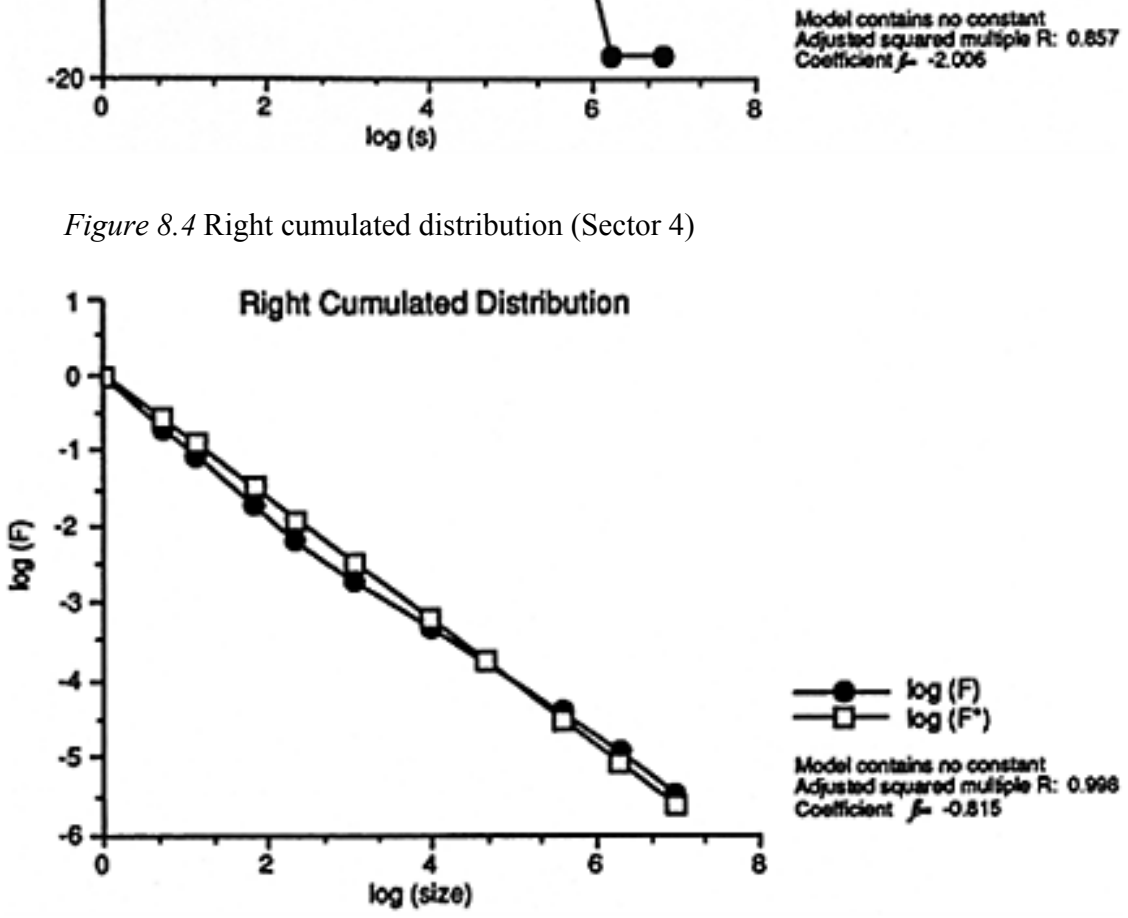
coviticiont $<-2.006$

Figure 8.5 Right cumulated distribution

Next, let us ask: what would happen if the general conditions of learning and selection underwent a generalized shock? After all, a few interpretations of the current patterns of "restructuring" in Western economies argue precisely that one is observing a major change in the "technoeconomic paradigm," associated with information technologies and, with a "post-Fordist" organization of production. (See for example, Freeman and Perez (1988)). All this - some add - implies a general competitive advantage for smaller firms (more rigorously, smaller business units) (Cf. Piore and Sabel 1984).

In this interpretation, one would predict that, first, also aggregate deviations from 
Pareto distributions, and, second, that these departures have a permanent nature. One actually observes in the 1970s and 1980s significant aggregate deviations from Pareto distributions (for evidence on Italy, see Barca (1985)), indicating a higher-than-average probability of growth of smaller size units. In our view, however, any inference on a competitive bias systematically favoring smaller size units might be deeply misleading.

It has been argued earlier that any observed structure is influenced by both age and size (via their effects on the probability of survival and growth). Suppose that, in fact, the emergence of a new "technoeconomic paradigm" based on microelectronic technologies has partly changed the knowledge base of innovation and widened the domain of unexplored technological opportunities. All this has plausibly enriched the opportunity of entry of new firms, and possibly also challenged the technological and organizational skills of older incumbents. In our model, this economy-wide change in learning regimes associated with the "devaluation" of older skills, may be captured by a negative influence of age on growth:

$$
g_{i, t}=g_{i, t=I}^{\delta(\alpha, i)} \cdot \varepsilon_{\mathrm{t}}
$$

Table 8.1 Deviations of actual aggregate size distributions from implied OLS estimate of Pareto distribution

\begin{tabular}{lllc}
\hline Range & $f(i)$ & $f^{*}(i)$ & deviation \\
\hline 1 & 43.50 & 49.79 & -12.63 \\
2 & 17.00 & 16.65 & 2.09 \\
$3-5$ & 17.84 & 16.69 & 6.89 \\
$6-9$ & 8.27 & 6.72 & 23.09 \\
$10-19$ & 7.50 & 5.05 & 48.37 \\
$20-49$ & 3.61 & 3.04 & 24.36 \\
$100-249$ & 0.61 & 0.62 & -0.83 \\
$250-499$ & 0.23 & 0.21 & 11.54 \\
$500-999$ & 0.08 & 0.10 & -27.60 \\
$1000+$ & 0.01 & 0.10 & -90.60 \\
\hline
\end{tabular}

We have simulated 10 years of such "shock" on growth opportunities and then calculated the deviation of the actual aggregate size distributions from the implied OLS estimate of a Pareto distribution. ${ }^{11}$

Table 8.1 reports the results, which look quite like the evidence reported by Barca (1985) on Italian Census data: the biggest business units grow less than average while small to medium units grow above average. However, in our interpretation, this is the outcome of technological novelty and not of size as such. New firms are generally smaller, but their advantage does not reside in their "smallness', but in their 
"newness" (they are carriers of technological and organizational innovations allowed by the new "paradigm").

Under what circumstances can this bias be permanent? If our approach is correct, a permanent bias in favor of relatively "new" (and, as a consequence, smaller) firms would require

a) the general disappearance of economies of scale in production, marketing, R\&D, etc., and,

b) the total lack of path-dependency and cumulativeness in learning.

We consider both circumstances as highly unlikely. Rather, we suggest, the process of exploration of a new "technoeconomic paradigm" is eventually leading to new "trajectories" of path-dependent learning. Older organizations and new ones that have become big as a result of their innovative success, most likely, are progressively internalizing the competences associated with the new paradigms. As a consequence, one should expect the growth process to return to a form similar to that described by equation 6.; and - as simulations not presented here show - the aggregate industrial structure to approach again a Pareto distribution.

\section{SOME CONCLUSIONS}

We have argued in this work that the nature of technological and organizational learning, jointly with the process of market selection, underlie the explanation of the observed boundaries between the activities that are internalized within corporate organizations and those that are mediated through the market. The characteristics of learning and selection account for the approximate scope for diversification by multiproduct firms. These regimes of learning and selection, specific to each industrial activity, determine also the variety of industrial structures that one observes. The relative stability over time of a Pareto-type distribution of firms (and business units) - it has been tentatively suggested on the grounds of model simulations - may simply result by the aggregation over sectoral structures showing significantly different boundaries between organizations and markets.

Further, we have argued, economy-wide discontinuities in the sources of innovation are likely to "shock" the size distribution of firms and business units by enlarging the "window of opportunity" of new entrants. However, long-term changes in the relative efficiency and competitiveness of small and younger firms vis-à-vis bigger and older ones would imply also a long-term fall on the importance of innovative experience and cumulative learning. Indeed, we are rather skeptical on any proposition suggesting that contemporary environments have become more "Darwinian" than in the past (that is, "learning" counts less and random mutation counts more; organizations decrease their abilities of coping with turbulent environments as compared with daring individuals...). Rather, we interpret the evidence on the industrial restructuring of the 1970s and 1980s as witnessing profound changes in the sources of corporate competitiveness, whichprogressively - older and younger organizations are learning to master. 


\section{ACKNOWLEDGMENTS}

Support of the research by the Italian Ministry of Research ("Progetti 40\%") is gratefully acknowledged. Part of this chapter is drawn from Dosi, Teece, and Winter (1992). 